\title{
PATTERN OF HOLLOW VISCUS INJURY IN BLUNT INJURY ABDOMEN - A RETROSPECTIVE STUDY IN A TERTIARY CARE CENTRE
}

\author{
R. Rajavelu1, A. Mohammed Imran Khan ${ }^{2}$
}

1 Professor, Department of General Surgery, Government Vellore Medical College. 2Junior Resident, Department of General Surgery, Government Vellore Medical College.

\section{ABSTRACT}

\section{BACKGROUND}

The objective of this study is to determine the presentation, anatomical distribution, diagnostic method, management and outcome of Hollow Viscus Injury (HVI) from blunt abdominal trauma.

\section{MATERIALS AND METHODS}

This was a retrospective cross-sectional study including patients with blunt abdominal trauma leading to Hollow viscus injury admitted at Government Vellore Medical College over a period of 2 years (January 2014 to January 2016).

- Data were retrieved from patient's medical records. Total 50 patients with Hollow viscus injury due to blunt abdominal trauma, who underwent laparotomy at our Institute were reviewed.

- Data regarding clinical presentation, anatomical distribution, management and outcome were recorded and analysed.

\section{RESULTS}

- The most common site of injury was ileum (19) followed by jejunum (13).

- There were 5 gastric perforations, 4 duodenal, 4 colonic, 4 sigmoidal and 1 rectal injuries.

- Road traffic accident was the most common mechanism of injury (57.2\%) followed by fall from height (36.4\%) and assault (6.4\%).

- Free gas under diaphragm on erect abdomen radiography was seen in $85.5 \%$ of cases, while preoperative CT abdomen was done in $11.6 \%$ of cases.

- Treatment consisted of simple closure of the perforation (66.5\%), resection and anastomosis (11.0\%) and stoma (22.5\%).

- Average hospital stay was $13 \pm 6$ days.

\section{CONCLUSION}

Fifty patients were enrolled into the study. Among them there were about thirty (60\%) male patients and twenty (40\%) female patients. The age range between 20 to 49 years were about $66 \%$ accounting to maximum population of blunt injury abdomen reported. Twelve patients (24\%) were in the age group below 20 years. Five patients were (10\%) above 50 years of age injuries following blunt injuries.

\section{KEYWORDS}

Hollow Viscus Injury (HVI); Blunt Abdominal Trauma; Diagnostic Modality; Complication; Mortality.

HOW TO CITE THIS ARTICLE: Rajavelu R, Khan AMI. Pattern of hollow viscus injury in blunt injury abdomen - a retrospective study in a tertiary care centre. J. Evolution Med. Dent. Sci. 2017;6(15):1164-1166, DOI: 10.14260/Jemds/2017/253

\section{BACKGROUND}

Small bowel injuries are more often seen in Blunt Injury Abdomen. Out of most commonly proposed mechanisms of small bowel injury some of them are.

- It could be caused due to compression forces acting over the small bowel causing its entrapment between blunt external source in front and the rigid spine behind.

- When there is increased intraluminal pressure in the bowel, it causes disruption of bowel wall integrity.

- Sudden deceleration forces, which can cause tears at the junction of fixed part and mobile segments of small bowel.

Financial or Other, Competing Interest: None.

Submission 14-01-2017, Peer Review 07-02-2017,

Acceptance 13-02-2017, Published 20-02-2017.

Corresponding Author:

Dr. R. Rajavelu,

Professor,

Department of General Surgery,

Government Vellore Medical College.

E-mail: rvstanley@gmail.com

DOI: $10.14260 /$ jemds $/ 2017 / 253$
- Manifestation of such injuries could be in the form of Laceration, Transection, Serosal Tears, Rupture and Subserosal haematoma.

- The fixed points of small bowel include - Duodeno-Jejunal Flexure, Ileocecal valve and Peritoneal attachments.

\section{MATERIALS AND METHODS}

The study was performed during a 2-year period from January 2014 to January 2016 in Government Vellore Medical College, Vellore. As this was a retrospective study, no informed or written consent was required for inclusion in the study. We included all the patients who were referred to our centre with blunt abdominal trauma who were diagnosed to have hollow viscus injury.

We included those Patients whose Medical Charts had Complete Data on -

- Baseline characteristics,

- Clinical findings, and

- Radiological workups. 


\section{Data were collected on -}

Age, sex, mechanism of injury, presentation, location of injury, associated injuries, treatment, mortality and morbidity. HVI diagnosis, operations and discharge/death was also recorded. Data was prospectively entered into a computer database.

\section{RESULTS}

Fifty patients were enrolled into the study. Among them there were about thirty (60\%) male patients and twenty (40\%) female patients. The age range between 20 to 49 years were about $66 \%$ accounting to maximum population of blunt injury abdomen reported. Twelve patients (24\%) were in the age group below 20 years. Five patients were (10\%) above 50 years of age.

Free gas under diaphragm in erect abdominal radiography was recorded in 33 patients, while preoperative abdominal CT scan/Ultrasonography was performed in 16 patients.

Exploratory laparotomy was performed in 38 patients based on clinical or radiological findings.

Ileum was the most common site of injury recorded in 19 patients followed by jejunum in 13 patients. There were 5 gastric perforations, 4 duodenal, 4 colonic, 4 sigmoidal and 1 rectal injuries.

The frequency of hollow viscus injury in our series is summarised in Figure 1.

Treatment consisted of simple closure of the perforation, resection and anastomosis and stoma. All gastric and duodenal injuries were treated by primary closure. Most of the small intestinal perforations were treated by primary closure, resection and anastomosis, while few required ileostomy. While two colonic injuries required diversion ileostomy, two rectosigmoidal injuries were treated by diversion colostomy followed by stoma closure at 3 months. Overall, 3 patients passed away due to HVI.

Associated injuries were present in 37 (21.38\%) patients. Intra-abdominal injuries were mainly to the liver. Extraabdominal injuries were mainly to the skeletal system. The mean hospital stay was $13.2 \pm 6.4$ (ranging from 7 to 30 ) days.

\begin{tabular}{|c|c|}
\hline Hollow Viscus & Frequency \\
\hline Ileum & 19 \\
\hline Jejunum & 13 \\
\hline Gastric & 5 \\
\hline Duodenum & 4 \\
\hline Colonic & 4 \\
\hline Sigmoid & 4 \\
\hline Rectum & 1 \\
\hline
\end{tabular}

Table 1. Frequency of Hollow Viscus Injury in 50 Patients with Blunt Abdominal Trauma referred to our Centre

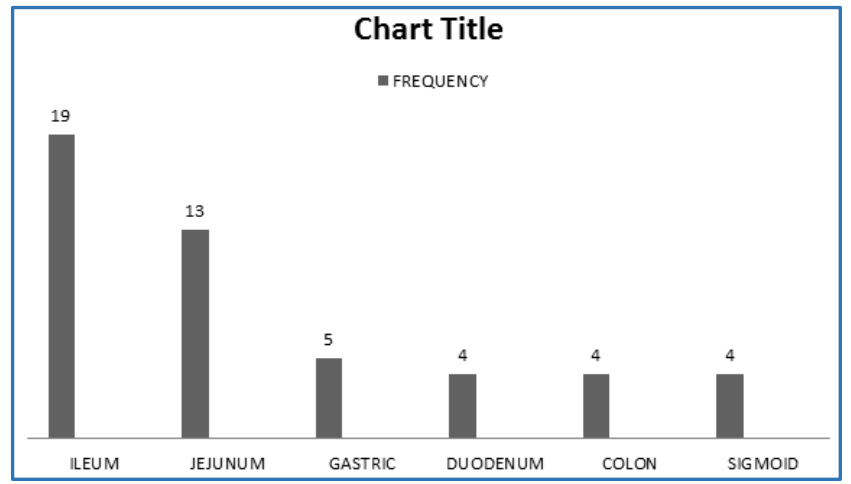

\begin{tabular}{|c|c|}
\hline Mechanism of Injury & Percentage \\
\hline RTA & 57.2 \\
\hline Fall from Height & 36.4 \\
\hline Assault & 6.4 \\
\hline Table 2. Mechanism of Injury in Hollow Viscus Injury \\
\hline
\end{tabular}

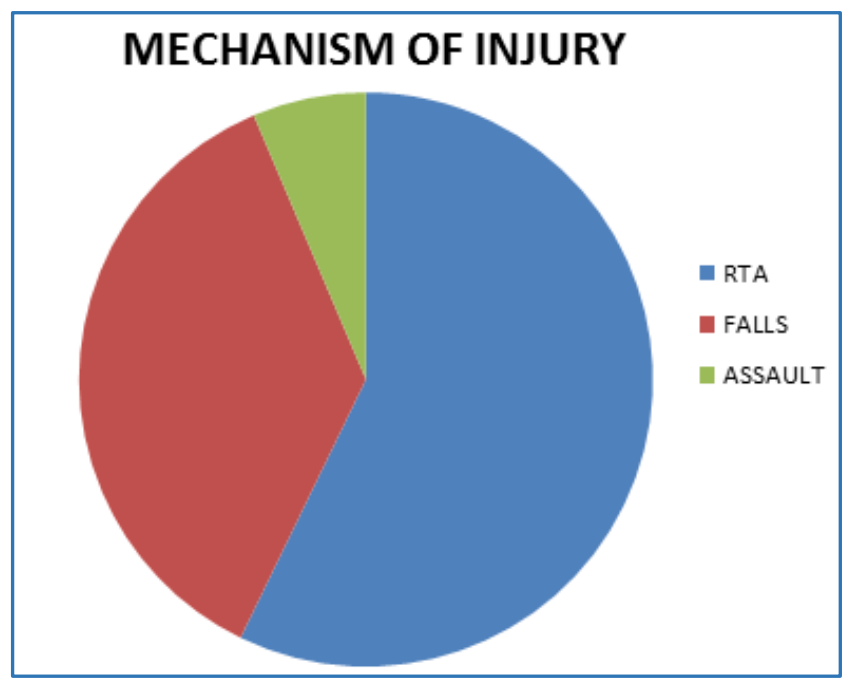

\begin{tabular}{|c|c|}
\hline Treatment & Percentage \\
\hline Primary Closure of the Perforation & $66.5 \%$ \\
\hline Resection and Anastomosis & $11.0 \%$ \\
\hline Stoma & 22.5 \\
\hline Table 3. Treatment Offered in Hollow Viscus Injury \\
\hline
\end{tabular}

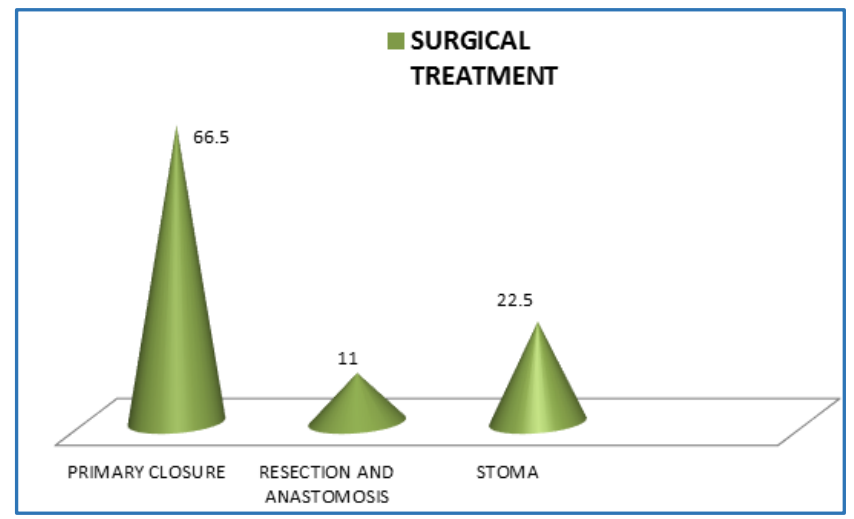

\section{DISCUSSION}

Hollow viscus injury are more often seen in Blunt Injury Abdomen. ${ }^{1}$ Out of most commonly proposed mechanisms of small bowel injury, only three is proven. 
- It could be caused due to compression forces acting over the small bowel causing its entrapment between blunt external source in front and the rigid spine behind. ${ }^{2}$

- When there is increased intraluminal pressure in the bowel, it causes disruption of bowel wall integrity.

- Sudden deceleration forces, which can cause tears at the junction of fixed part and mobile segments of small bowel. ${ }^{3}$

\section{Manifestation of such Injuries could be in the form of -}

- Laceration.

- Transection.

- Serosal tears.

- Rupture.

- Subserosal haematoma. ${ }^{4}$

\section{The Fixed Points of Small Bowel include -}

- Duodeno-Jejunal flexure.

- Ileocecal valve.

- Peritoneal attatchments. ${ }^{5}$

Apart from intra-operative findings, an important external finding leading to diagnosis of small bowel injury will be Seat-Belt Mark. ${ }^{6}$

Seat belt syndrome ${ }^{7}$ is caused by sudden deceleration forces acting between posterior abdominal wall and vertebra causing injury to the organs in between due to one or other mechanisms described above.

\section{Investigation of these cases includes}

- X-ray abdomen erect to rule out gas under diaphragm.

- USG abdomen to detect free fluid abdomen.

- FAST. ${ }^{8}$

- DPL.

In such seat-belt injuries, there is also risk of lumbar vertebra fracture known as Chance fracture. ${ }^{9}$

\section{CONCLUSION}

Fifty patients were enrolled into the study. Among them there were about thirty (60\%) male patients and twenty (40\%) female patients. The age range between 20 to 49 years were about $66 \%$ accounting to maximum population of blunt injury abdomen reported. Twelve patients $(24 \%)$ were in the age group below 20 years. Five patients were $(10 \%)$ above 50 years of age. Injuries following Blunt Injuries.
Most cases of hollow viscus injury due to blunt abdominal trauma, presence of signs of peritonitis with obliteration of liver dullness supported by plain x-ray abdomen in erect posture are diagnostic and exploration is mandatory. Time scale of surgical intervention is an important prognostic factor. It is interesting to note that most of the haemodynamically stable patients of solid viscera injury are managed conservatively, while rarely in hollow viscus injury. Followup of a suspected case of hollow viscus injury is more clinical than imaging based even in haemodynamically stable patients.

\section{REFERENCES}

[1] TraumaRegister $\mathrm{DGU}(\circledR) .20$ years of trauma documentation in Germany-actual trends and developments. Injury 2014;45(Suppl 3):S14-9.

[2] Fakhry SM, Brownstein M, Watts DD, et al. Relatively short diagnostic delays ( $<8$ hours) produce morbidity and mortality in blunt small bowel injury: an analysis of time to operative intervention in 198 patients from a multicenter experience. J Trauma 2000;48(3):408-14.

[3] Bruscagin V, Coimbra R, Rasslan S, et al. Blunt gastric injury. A multicentre experience. Injury 2001;32(10):761-4.

[4] Magu S, Agarwal S, Gill RS. Multi detector computed tomography in the diagnosis of bowel injury. Indian J Surg 2012;74(6):445-50.

[5] Swaid F, Peleg K, Alfici R, et al. Concomitant hollow viscus injuries in patients with blunt hepatic and splenic injuries: an analysis of a national trauma registry database. Injury 2014;45(9):1409-12.

[6] Abbasi HR, Mousavi SM, Akeri TA, et al. Pattern of traumatic injuries and injury severity score in a major trauma center in Shiraz, Southern Iran. Bull Emerg Trauma 2013;1(2):81-5.

[7] Pekkari P, Bylund PO, Lindgren $\mathrm{H}$, et al. Abdominal injuries in a low trauma volume hospital-a descriptive study from northern Sweden. Scand J Trauma Resusc Emerg Med 2014;22:48.

[8] Arikanoglu Z, Turkoglu A, Taskesen F, et al. Factors affecting morbidity and mortality in hollow visceral injuries following blunt abdominal trauma. Clin Ter 2014;165(1):23-6.

[9] Matsushima K, Mangel PS, Schaefer EW, et al. Blunt hollow viscus and mesenteric injury: still underrecognized. World J Surg 2013;37(4):759-65. 